\title{
Política Social e Direitos: perspectivas contemporâneas
}

\author{
Ariane Paiva $^{1}$ \\ Monica Senna² \\ Lenaura Lobato ${ }^{3}$
}

\section{Introdução}

A história da Política Social, compreendida como resposta do Estado e da sociedade aos conflitos oriundos dos interesses antagônicos entre as classes sociais e de suas consequentes desigualdades socioeconômicas, ou seja, como uma das intervenções públicas nas expressões da questão social, está diretamente associada às lutas por direitos e à construção da cidadania nas sociedades capitalistas.

Como área de conhecimento que ganhou notoriedade ao longo do século XX, o campo de análise de políticas públicas inclui os estudos das particularidades da política social como gênero de políticas públicas adotada em diferentes regiões e períodos históricos, incorporando uma vasta variedade de disciplinas e direcionamentos teórico-metodológicos. O campo reivindica as políticas sociais como mediações institucionais e normativas nas relações sociais capitalistas, que envolvem processos contraditórios na trama entre o desenvolvimento econômico, as disputas políticas globais e domésticas entre nações e as lutas de movimentos sociais, partidos políticos e organizações variadas por proteção e direitos sociais. Este campo tem alimentado as pesquisas do Serviço Social brasileiro, bem como tem sido influenciado pelas pesquisas dessa área.

O estudo hegemônico da política social na área de Serviço Social no Brasil tem dado ênfase à sua natureza na reprodução das relações da ordem capitalista, o que envolve identificar seus processos e sujei- 
tos, envolvidos em sua elaboração e implementação em experiências concretas, considerando as mudanças no mundo do trabalho e nas mediações da política social com a formação e o trabalho profissional.

Considerando as trocas interdisciplinares no campo da análise de políticas, a organização desta revista buscou selecionar textos resultantes de estudos e investigações de distintas áreas de conhecimento e perspectivas analíticas que tratassem das questões referentes à Política Social e da cidadania no Brasil e na América Latina como mediação da relação entre Estado e Sociedade. O debate sobre os direitos sociais nunca saiu da agenda dos estudos das diferentes ciências desde o século XIX, quando se iniciaram as primeiras experiências de ações públicas para garantir proteção social a determinados grupos e segmentos sociais compreendidos entre os mais vulnerabilizados pelos sistema de organização da produção e reprodução capitalista e aos trabalhadores, que passaram a reivindicar participação no sistema político e melhores condições de trabalho e de vida, com a consolidação da sociedade de mercado (POLANYI, 2012).

Apesar da política social não se resumir aos aspectos do direito, suas legislações e normas jurídicas, certamente também não podem ser desconsideradas suas relações orgânicas. Neste sentido, a política social se aproxima do debate da cidadania, compreendida como "o conjunto de direitos positivos que vinculam o cidadão ao seu Estado" (FLEURY, 1994) e aos complexos processos que envolvem a declaração dos direitos nas sociedades democráticas liberais e as formas concretas para sua materialização, considerando as desigualdades estruturantes da ordem capitalista mundial, que envolvem uma multiplicidade de marcadores como classe, gênero, raça/etnia e nacionalidade.

Estudar as particularidades desses processos na região da América Latina, considerando suas históricas realidades de colonização, expropriação e suas formas de resistência e organização social na ordem mundial são fundamentais para a compreensão do desenvolvimento de suas instituições, a constituição de seus processos democráticos e dos 
direitos sociais. Neste sentido, como aponta Galeano (2020, p.18), estudar a América Latina é, decerto, também considerar as diferenças regionais, as opressões de países pequenos pelos maiores, seus vizinhos, e as "fronteiras adentro de cada país". Assim, nosso interesse em estudar o Brasil. Buscamos, portanto, neste número da revista O Social em Questão $n^{\circ} 52$, situar as questões atuais e contemporâneas que vinculam a política social às disputas por direitos nessa região particular.

Os estudos se situam pelas mudanças estruturais que o mundo capitalista vem sofrendo desde a década de 1970. A crise estrutural tem imposto obstáculos ao acúmulo de capital e tensionado as lutas de classes. Nos dizeres de Dardot e Laval (2016) houve uma "grande virada" mediante a implementação de políticas qualificadas, ao mesmo tempo, como "conservadoras" e neoliberais". Parte da longa onda recessiva que se abriu a partir de então, em 2006, os EUA foram os primeiros a sentirem os efeitos da crise das hipotecas subprime, acompanhada, em 2008, da "falência" do sistema financeiro mundial (HARVEY, 2011). Esse processo trouxe inúmeras consequências não só econômicas, mas também políticas e sociais, reconfigurando as relações entre Estado, sociedade e mercado, com efeitos diversos para os países de capitalismo central e periférico.

Andrew Gamble resumiu esse novo rumo na frase: "Economia livre, Estado forte". A expressão tem o mérito de destacar o fato de que não estamos lidando com uma simples retirada de cena do Estado, mas com um reengajamento político do Estado sobre novas bases, novos métodos e novos objetivos (DARDOT e LAVAL, 2016, p.190).

A ascensão de governos conservadores e o aprofundamento da agenda neoliberal têm incidido nos sistemas de proteção social dos diversos países e afetado os distintos padrões de cidadania e os direitos sociais, considerando suas singularidades. Identificam-se, porém, tendências de políticas austeras, aumento do desemprego, medidas protecionistas e discursos nacionalistas, fechamento 
de fronteiras para a migração, propostas de reformas trabalhistas, dentre outras medidas associadas a um novo padrão de desenvolvimento capitalista que reorganiza a divisão internacional do trabalho e fragiliza as formas de proteção social.

A essas necessárias análises macrossociológicas sobre o Estado capitalista se somam, mais recentemente, esforços para examinar o processo de construção em sua face inversa, o desmantelamento de políticas públicas como fenômenos complexos e multidimensionais, constantemente atravessados por dinâmicas sociais e políticas que influenciam a tomada de decisões, a qual envolve, por sua vez, uma multiplicidade de sujeitos sociais inseridos em arenas institucionais e contextos sociais e políticos específicos. Parte da produção acadêmica recente no campo da análise de politicas públicas no Brasil tem buscado avançar nessa direção, examinando os processos que concorrem para a entrada de um tema na agenda governamental e na formulação de políticas públicas (CAPELLA, 2018). No mesmo esteio analítico situam-se estudos voltados ao exame da implementação de políticas enquanto um campo também atravessado por conflitos, tensões e negociações entre diversos atores sociais, com interesses distintos e dispondo de recursos assimétricos e capacidades também distintas de influenciar a arena decisória. Mais do que a mera execução das diretrizes contidas no desenho original de uma política, a implementação envolve um conjunto de interações entre esses diferentes sujeitos e certo grau de discricionariedade dos chamados agentes implementadores, que incidem nos resultados das políticas (LOTTA, 2018).

Os trabalhos selecionados se relacionam com as reformas dos sistemas de proteção social e dos padrões de cidadania em curso e identificam tendências contemporâneas da política social em diferentes realidades e áreas distintas, considerando relações de poder em disputa e a atuação dos sujeitos sociais. Foram selecionados nove artigos e duas resenhas, que separamos por dois fios condutores. O primeiro, trata da conjuntura de crise do capitalismo mundial e como os siste- 
mas de proteção social estão afetados - o que envolve leis, justiça, as políticas sociais e os direitos. O segundo foi deslocado para a política social como campo de conhecimento teórico-metodológico que inclui aspectos da implementação ou execução de políticas públicas e seus variados processos de análise.

\section{Crise mundial do capitalismo e a desproteção social em curso}

Durante o século XX e início do XXI, foram constituídas diferentes formas de proteção social, compreendida aqui, como o conjunto de ações estabelecidas pelo Estado moderno no Ocidente para atender as demandas da relação entre capital e trabalho e das mobilizações e reivindicações por direitos humanos e sociais. Após a década de 1980, temos visto processos de constantes disputas na conformação desses sistemas de proteção social, com avanços e perdas que variam no tempo e no espaço.

Em um processo de acirramento da crise estrutural do capital, algumas mudanças têm contribuído para que milhares de trabalhadores passem à categoria de "desprotegidos" pelos sistemas históricos de proteção dos Estados, como as reformas trabalhistas e previdenciárias, incluindo as flexibilizações nas legislações sociais e mudanças procedimentais e burocráticas que interferem diretamente no acesso aos direitos dos trabalhadores e suas famílias. Esta é uma realidade em vários países, com configurações específicas, e de acordo com a capacidade de resistência e mobilização dos trabalhadores, sindicatos, partidos políticos, dentre outros. Esse processo de desmonte dos direitos sociais tem sido acompanhado pela desproletarização, com a passagem do emprego sólido para o líquido (POCHMANN, 2021).

O primeiro artigo, intitulado: "O trabalho intermitente: Uma análise comparada", escrito por Leandro Luciano Silva Ravnjak, Giovana Maria Mendes Rodrigues e Victor Manoel Rangel Soares, traz a análise da aprovação do trabalho intermitente no Brasil, incluído na aprovação da lei $n^{\circ} 13.467$, de julho de 2017, como forma de desregulamentação 
dos direitos trabalhistas, sob influência de reformas em outros países, como Portugal, Reino Unido, Itália e Espanha. Os autores evidenciam pontos de convergência e de distanciamento do trabalho intermitente no Brasil e nos demais países analisados, e buscam demonstrar a relação entre a precarização das relações de trabalho com a implementação da modalidade intermitente.

Sobre as formas de desproteção social, consideramos, além da perda de direitos até então garantidos por lei, os processos que impedem os sujeitos a usufruírem desses direitos e a precarização dos serviços públicos que garantem diversas dimensões para a sobrevivência da população, como a saúde, a alimentação, a moradia etc. Particularmente no Brasil, além das mudanças nas relações trabalhistas e previdenciárias, o país tem passado, nos últimos anos, por uma redução no financiamento das políticas sociais, principalmente em razão da aprovação, em 2016, da Emenda Constitucional $n^{\circ}$ 95, conhecida como a Emenda Constitucional do Teto dos Gastos Públicos, que alterou a Constituição Federal de 1988 e instituiu um novo Regime Fiscal. Essa medida instituiu o congelamento dos gastos públicos por vinte anos, inclusive nas áreas sociais, o que tem gerado um impacto desastroso na oferta dos serviços de saúde, educação e assistência social, como as principais políticas sociais destinadas a atender o público que se encontra em maiores vulnerabilidades socioeconômicas. O artigo “(Des) financiamento e (des) proteção social: o abate da 'prima pobre' da Seguridade Social”, escrito por Diana Delgado, Erika dos Santos Tolentino, Mara Cristina Fernandes Barbosa, Ricardo William Guimarães Machado, e Nilza Rogéria de Andrade Nunes, situou essa realidade por meio dos impactos no financiamento da política de assistência social, política que compõe a seguridade social brasileira. A esse processo de diminuição dos recursos financeiros para a política, os autores utilizam a conceituação de desfinanciamento, em que o Fórum de Secretários Estaduais de Assistência Social define como a retirada progressiva de recursos de uma série histórica de ampliação que vinha sendo garantida para a manutenção da rede de atendimento dos serviços. 
Seguindo a lógica de desmonte dos direitos sociais em diversos países do globo, aqui na região da América Latina temos acompanhado, nos últimos anos, inúmeras mobilizações populares, principalmente em torno dos direitos políticos e sociais. O texto produzido por Brenda Luanda Silva Costa e Mônica de Castro Maia Senna, O modelo privatizado da previdência social chilena e a pandemia de covid-19: legado e tendências da desproteção social, aborda o modelo de capitalização privada do Chile implementado após a década de 1970 no contexto de implementação das políticas neoliberais no país e que mostrou ao mundo sua ineficiência em termos da garantia de direitos, acentuando ainda a desproteção social no contexto de pandemia da covid-19 que assolou o mundo em 2020.

O texto Direitos Humanos no Brasil - O $3^{\circ}$ Programa Nacional de Direitos Humanos e a Proposta de Revisão pelo Governo Bolsonaro, de autoria de Emanuele Dalpra Afonso, buscou apresentar o que se considera, na bibliografia especializada sobre a temática, a política de direitos humanos stricto sensu. Transversal às políticas sociais, essa política, apesar de estar na pauta dos governos federais no Brasil desde a década de 1990, não se institucionalizou de forma a garantir continuidade durante os diferentes governos. Há, porém, uma inflexão após a eleição do governo de extrema direita, representado pelo Presidente Jair Bolsonaro (2019-2022), que tem sido marcado por suas características conservadora e antidemocrática. O governo propôs a revisão do documento que institui o Programa Nacional de Direitos Humanos sem a participação popular e tem tomado medidas que vem fragilizando os direitos de grupos particulares.

\section{Política Social como campo de conhecimento: análise de políticas públicas}

Os textos seguintes abordam aspectos da análise de políticas com atenção aos aspectos teórico-metodológicos e experiências de implementação de políticas brasileiras. O primeiro texto é intitulado: Re- 
visão Panorâmica da Análise das Políticas Públicas de Gênero no Brasil (2016-2020), em que os autores Ana Rebeca Oliveira Cirilo e Rafael Fernandes de Mesquita se preocupam em investigar se as políticas de gênero conseguiram se consolidar no campo de análise das políticas públicas, utilizando o estudo bibliométrico.

Após esse texto que abre esta seção, os demais artigos possuem em comum os estudos de dimensões da implementação de políticas. Educação, Desigualdade e Proteção social, de Margareth Correa Silva e Janaína Specht da Silva Menezes buscaram identificar aspectos da desigualdade social na educação a partir de análise bibliográfıca e documental, situando o conceito como multidimensional e ultrapassando a esfera econômica. Outro artigo selecionado nesse campo foi: Efeitos sociais derivados da implementação de políticas públicas: uma análise do Programa Bolsa-Família, de Marisa da Conceição Teixeira, Breynner Ricardo de Oliveira. A partir de entrevistas com profissionais da burocracia do "nível de rua", as autoras trouxeram análises sobre a implementação do Programa Bolsa Família em um município de Minas Gerais, com o recorte a partir das condicionalidades educacionais impostas pelo referido programa.

Depois, segue-se a outro estudo produzido por Taiane Damasceno da Hora, Ariane Rego de Paiva e Ludmila Fontenele Cavalcanti, Análise do atendimento a crianças e adolescentes vítimas de abuso sexual em duas unidades municipais do Rio de Janeiro, que analisou a disponibilidade de recursos nos serviços de atendimento para crianças e adolescentes vítimas de abuso sexual na perspectiva dos profissionais e gestores da rede de saúde do município do Rio de Janeiro. Por último, o manuscrito A política de assistência farmacológica e os critérios do fornecimento judicial de medicamentos no Rio Grande do Sul, escrito por Joice Schroer, Cibele Cheron, Julice Salvagni, Renato Koch Colomby, estuda a política pública de assistência farmacológica, e analisa os fundamentos das decisões judiciais a fim de verificar se existem elementos que indicam atenção aos critérios definidos pelo gestor pú- 
blico, e sua respectiva consequência na execução da saúde no âmbito coletivo. Seus resultados demonstram que o direito à saúde por meio da assistência farmacológica depende de maior integração entre judiciário, profissionais e gestores do SUS.

Ao final da revista, duas resenhas abordam temas atuais das políticas sociais. A primeira, de Renata Venturim Bernardino, chama-se A pandemia do coronavírus como produto da dinâmica global do capitalismo e seus impactos sobre a classe trabalhadora, e se refere à publicação de 2020 do livro Coronavírus: O Trabalho Sob Fogo Cruzado, de Ricardo Antunes, que analisa a situação dos trabalhadores e a precarização do trabalho durante a grave crise sanitária produzida pelo coronavírus. Ricardo Antunes enfoca a relação entre a pandemia do coronavírus e o sistema capitalista atual e demonstra a situação dos trabalhadores sob o fogo cruzado entre a necessidade de proteção e sobrevivência. Finaliza sua obra destacando que a pandemia mostrou que a invenção de um novo modo de vida deve ser um imperativo de nosso tempo.

A outra resenha é um estudo do livro de Tatiana Brettas, Capitalismo dependente, neoliberalismo e financeirização das políticas sociais no Brasil, também de 2020. O autor, João Vitor Bitencourt, faz uma análise dos quatro capítulos da obra, destacando sua importância para os estudos da política social e do Serviço Social, no campo dos estudos da Teoria Marxista da Dependência (TMD).

Esperamos que esta publicação seja lida, relida e incorporada pelos analistas de políticas públicas, em especial aos que se dedicam ao estudo das políticas sociais e dos direitos. Boa leitura!

\section{Referências}

CAPELLA, Ana Cláudia N. Formulação de Políticas. Brasília: Enap, 2018.

DARDOT, Pierre; LAVAL, Christian. A nova razão do mundo: ensaio sobre a sociedade neoliberal. 1 ed. São Paulo: Boitempo, 2016. 
FLEURY, S. Estado sem cidadãos: seguridade social na América Latina [online]. Rio de Janeiro: Editora FIOCRUZ,1994.

GALEANO, Eduardo. As veias abertas da América Latina. Porto Alegre, RS: L\&PM, 2020.

HARVEY, David. O enigma do capital e as crises do capitalismo. São Paulo, SP: Boitempo, 2011.

LOTTA, Gabriela. Burocracia, redes sociais e interação: uma análise da implementação de políticas públicas. Revista de Sociologia e Política v. 26, n. 66, p. 145-173, 2018.

POCHMANN, Márcio. O emprego que virou suco. Blog Outras Palavras. Publicado em 18/10/2021. Disponível em: https://outraspalavras.net/trabalhoeprecariado/o-emprego-que-virou-suco/ Acesso em: 18/10/2021

POLANYI, Karl. A grande transformação: as origens da nossa época. 2 ed. Rio de Janeiro: Elsevier, 2012

SENADO FEDERAL. Emenda Constitucional do Teto de Gastos Públicos. 15/12/2016. Disponível em: https://www12.senado.leg.br/noticias/materias/2016/12/15/promulgada-emenda-constitucional-do-teto-de-gastos Acesso em: 20/10/2021

\section{Notas}

1 Assistente Social formada pela Escola de Serviço Social da UFRJ, Mestre e Doutora pelo Programa de Estudos Pós-Craduados em Política Social da UFF/Niterói, Professora Adjunto do Departamento de Serviço Social da PUC-Rio, ORCID 0000-0002-5827-6355, e-mail: arianepaiva@puc-rio.br

2 Assistente Social. Mestre e Doutora em Ciências - Saúde Pública. Professora Titular do Programa de Pós-Graduação em Política Social e da Escola de Serviço Social da Universidade Federal Fluminense, Brasil. Pesquisadora CNPq. E-mail: monica_senna@id.uff.br. http://lattes.cnpq.br/6254529022390636. ORCID: https://orcid.org/0000-0003-2161-7133

3 Socióloga (IFCS-UFRJ), doutora em Saúde Pública (ENSP-FIOCRUZ), professora titular, coordenadora do Programa de Estudos Pós-Graduados em Política Social - Escola de Serviço Social, Universidade Federal Fluminense. ORCID: 00000002-2646-9523. Email: lenauralobato@id.uff.br 